\title{
Epidemiological study of the consumption of psychotropic's in the northeast region of Argentina
}

\begin{abstract}
Objective: To evaluate the consumption of psychotropic's in the northeast region of Argentina from 1997 to 2000, expressed as defined daily dosis (DDDs).

Methods: Data were collected from drug providers that supply the different pharmaceutical specialties, and community pharmacies, which prepare pharmaceutical compoundings, according to the established legal requirements in our country.

Results: During this period 36.318.960 DDDs of pharmaceutical specialties were distributed in the following order: 29.357.168 DDDs correspond to anxiolytics and hypnotics; 3.677.099 DDDs to antidepressants and 3.284.693 antipsychotics. On the other hand, 1.219.987 DDDs of pharmaceutical compoundings were prepared: 370.846 DDDs of anxiolytics and hypnotics; 700.824 of antidepressants and 148.314 of antipsychotics.

Conclusions: This work shows the importance to evaluate the consumption of psychotropic's in order to contribute significantly to the implementation of rational use of these drugs.
\end{abstract}

Keywords: consumption, drug utilization, epidemiological study, pharmaceutical specialties, pharmaceutical compounding, psychotropic's, rational use
Volume 7 Issue 3 - 2019

\author{
Gerardo Fridman,' Amelio Presman² \\ 'Department of Pharmaceutical Technology of School of \\ Pharmacy and Biochemistry, University of Buenos Aires, \\ Argentina \\ ${ }^{2}$ Physician Specialist in Psychiatry, Corrientes, Argentina
}

\begin{abstract}
Correspondence: Gerardo Fridman, Doctor Degree, Pharmacist of Corrientes Pharmacy, Corrientes and Member of the Clinical Pharmacy, Department of Pharmaceutical Technology of School of Pharmacy and Biochemistry, University of Buenos Aires, Argentina, Email gfridman 10@hotmail.com
\end{abstract}

Received: April 23, 2019 | Published: May 13, 2019

\section{Introduction}

Statistical studies are regularly carried out to assess the increase or decrease in the use of different medicines, ${ }^{1-3}$ to analyze the factors influencing drug use. ${ }^{4}$ Monitoring drug utilization contributes greatly to the evaluation of pharmacotherapeutic attitudes in practice and to the determination of factors that have an effect on drugs consumption. ${ }^{5}$ The consumption of psychotropic's is a worldwide problem $^{5}$ which must be considered following their rational use. Its growing consumption and the acknowledgment of the psychical factor in almost every disease, lead us to the need of estimate their utilization in the community pharmacies. In this way the pharmacist can inform about the appropriate use of psychotropic's preventing or diminishing the abuse ${ }^{6-8}$ and their side effects. ${ }^{9-12}$ Drug utilization studies have particular significance in condition of limited financial resources that cause insufficient production of essential drugs, and shortage of drug supply. ${ }^{5,13,14}$ Moreover this study may be useful for the promotion and evaluation of educational and informational effort associated with rational pharmacotherapy. ${ }^{5}$ Due to the lack of data about the use of these drugs in our country, the aim of this study is to evaluate the consumption of psychotropic's expressed in DDDs in the Northeast region of Argentina during the period of 1997 to 2000, and to compare the pharmaceutical specialties supplied by drug providers with pharmaceutical compoundings dispensed by community pharmacies, expressed as defined daily dosis (DDDs).

\section{Materials and methods}

The study population comprised outpatients of 25 to 70 years old, resident in the Northeast region of Argentina. This region is constituted by four provinces (Corrientes, Misiones, Chaco and Formosa), which has almost 1.200.000 inhabitants. In order to analyze the consumption of psychotropic's, these drugs were classified according to pharmacological group, such as: anxiolytics/ hypnotics, antidepressants, antipsychotics and expressed as DDDs (defined daily dose). The collected psychotropic drug consumption data were obtained from records of two drug providers that distributed
$67 \%$ of all the pharmaceutical specialties in the region with the following information: brand name of drug, origin, dosage form and price of the drug. Other data were obtained from prescriptions issued by psychiatrics, processing all the pharmaceutical compoundings prepared according the established legal requirements in our country and which were dispensed to outpatients in community pharmacies in Northeast Region of Argentina. This data included patient's name, diagnoses, proprietary drug name, dosage form, dosage regimen, quantity dispensed, price of the drugs and data of dispensing. All data about pharmaceutical specialties and pharmaceutical compoundings were obtained by records of the drugs providers and community pharmacies according to the statements of the "Argentine Psychotropic Law' (Law 19.303) and the requirements of our 'Pharmacy Law' (Law 17.565). From this data-base, the real psychotropic drug utilization was established and the most prescribed psychotropic drugs in the period 1997-2000 were registered.

\section{Results and discussion}

The study population comprised outpatients of 25 to 70 years old, resident in the Northeast region of Argentina. This region is constituted by four provinces (Corrientes, Misiones, Chaco and Formosa), which has almost 1.200 .000 inhabitants. Table 1 show the drug used in every pharmacological group. In Figures 1, 2, 3 and 4 are shown the consumption patterns of pharmaceutical specialties of psychotropic drugs dispensed in the pharmacies.

As can be seen in Figure 1, it was observed a highly marked predominance of anxiolytics/hypnotics group supplied in 1997. Our results show a low consumption of them in January, increasing in March and April, with a peak in June. The antidepressants and the combinations of psychotropic drugs showed a similar pattern. ${ }^{15,16}$ It is to note that the consumption of these groups of drugs decreased from September to December, due to delivery problems.

In Figure 2 we can observed that March, June and December were the months with the most consumption of psychotropic's in 1998. As 
other authors have found, the higher prevalence of the use of these drugs in March and June was result of seasonal changes. ${ }^{17,22}$ Although, the anxiolytics/hypnotics group was the most outstanding (compare Figure 1 and Figure 2), this pattern of consumption was not similar with the finding of other epidemiological study. ${ }^{5}$

Figure 3 shows a similar pattern of psychotropic drugs consumption during 1999 as can be seen in Figure 1 \& Figure 2. We can also observe that although the prevalence of the anxiolytics/hypnotics group was during all the year, these drugs increased considerably in April, September and December. ${ }^{18-23}$ We note that the year 2000 was the year of the most consumption of psychotropics (Figure 4). In this case the prevalence of the anxiolytics/hypnotics group was higher in March, May, August and December. ${ }^{18-23}$ We also observe that the antipsychotics showed the lowest consumption in all the years studied (see Figures 1, 2, 3 and 4).

Table I Drug used in every pharmacological group

\begin{tabular}{llll}
\hline Anxiolitics/Hipnotics (BZD) & Anxiolitics/Hipnotics (Not BZD) & Antidepressants & Antipsychotics \\
\hline Alprazolam & Buspirone & Amitriptyline & Amisulpride \\
Bromazepam & Zolpidem & Bupropión & Bromperidol \\
Clobazam & Zopiclona & Citalopram & Chlorpromazine \\
Clonazepam & & Clomipramine & Clotiapine \\
Clorazepate & Desipramine & Flusperilene \\
Chlordiazepoxide & Fluoxetine & Haloperidol \\
Diazepam & Fluvoxamine & Levomepromazine \\
Estazolam & Imipramine & Pimozide \\
Flunitrazepam & Mianserine & Pipotiazide \\
Flurazepam & Mirtazapine & Prometazine \\
Ketazolam & Nefazodone & Propericiazine \\
Ethyl Loflazepate & Nortriptyline & Quetiapine \\
Lorazepam & Paroxetine & Risperidone \\
Midazolam & Sertraline & Sulpiride \\
Nitrazepam & Tranylcypromine & Thioridazine \\
Oxazepam & Trazodone & Trifluoperazine \\
Prazepam & Trimipramine & Zuclopentixol \\
\hline
\end{tabular}

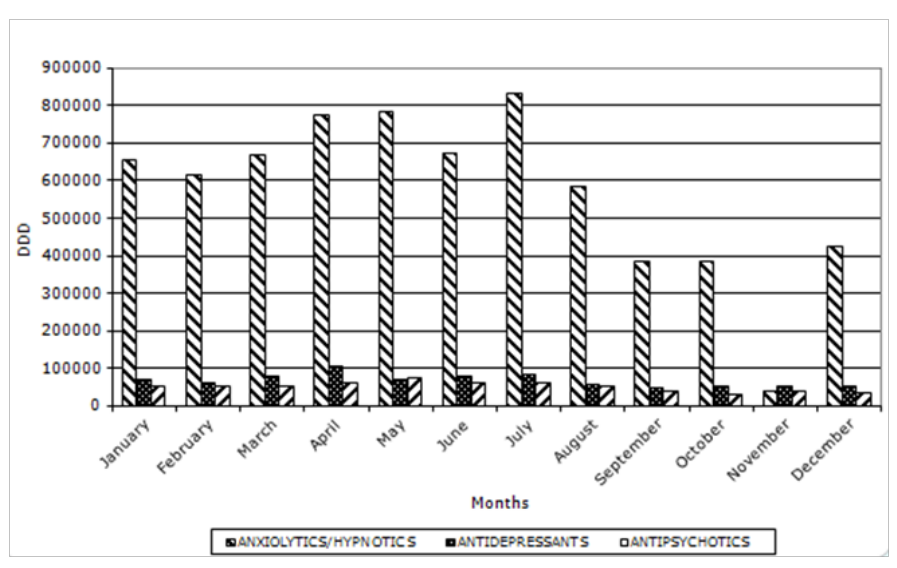

Figure I DDD of pharmaceutical specialties distributed by drug providers in 1997.

In Figures 5-8 are shown the prescriptions dispensed as pharmaceutical compoundings by community pharmacies in the Northeast region of Argentina in the same period of the study: 1997-2000. In agreement with other studies we observe that the antidepressants are more commonly prescribed than anxiolytics and hypnotics. ${ }^{5}$ We can also noted peaks of higher consumption of antidepressants in March, July and December which, in our country, correspond to autumn, winter and summer respectively. This increase was accorded with the seasonal affective disorders, as shown by others. ${ }^{18-23}$

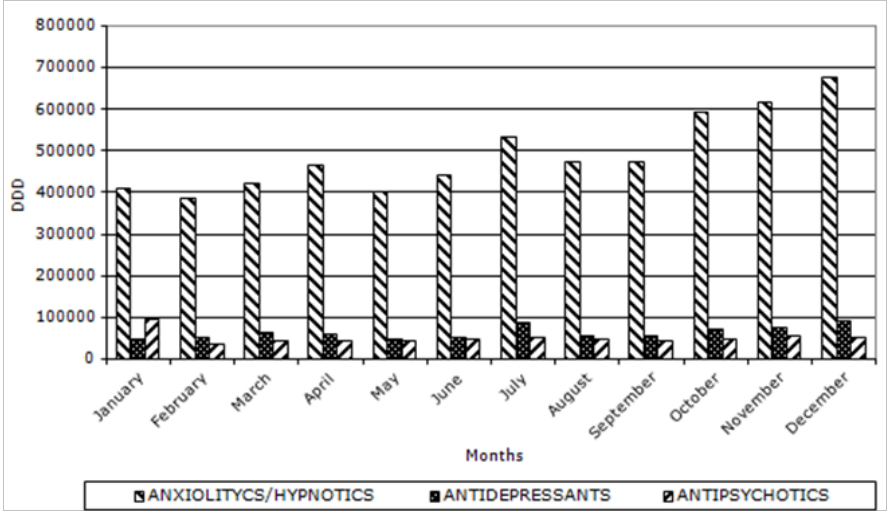

Figure 2 DDD of pharmaceutical specialties distributed by drug providers in 1998.

It is to note that in 1999 the consumption of psychotropic pharmaceutical compoundings dispensed by community pharmacies shows some differences respect to 1997, 1998 and 2000 (compare figure 7 with 5,4 and 8 ). As can be seen in the Figure 6 it has an unusual 
peak in May and decreased in July. Our results show also marked differences between the different groups of psychotropic's prescribed as pharmaceutical specialties and pharmaceutical compoundings. We observe that: the pharmaceutical specialties of anxiolytics/hypnotics were the most consumed drugs, meanwhile the pharmaceutical compounding of psychotropic combination and antidepressant were the most dispensed in the community pharmacies.

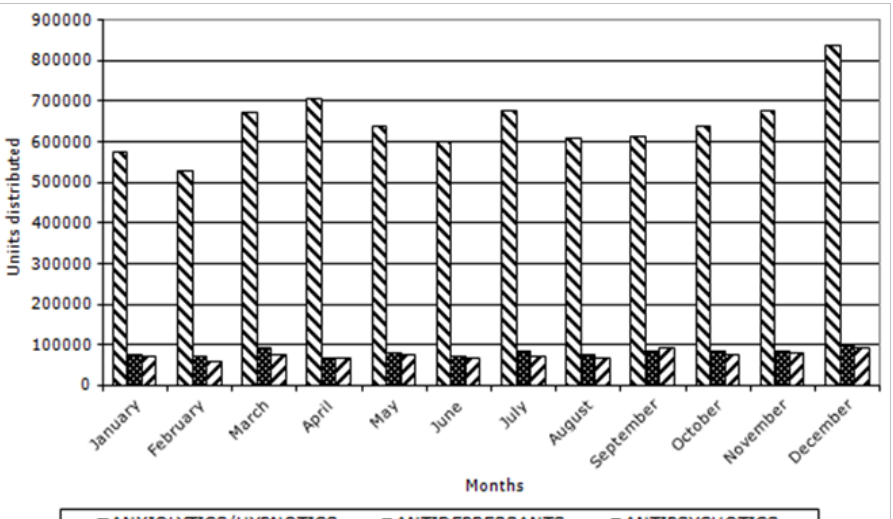

Figure 3 DDD of pharmaceutical specialties distributed by drug providers in 1999.

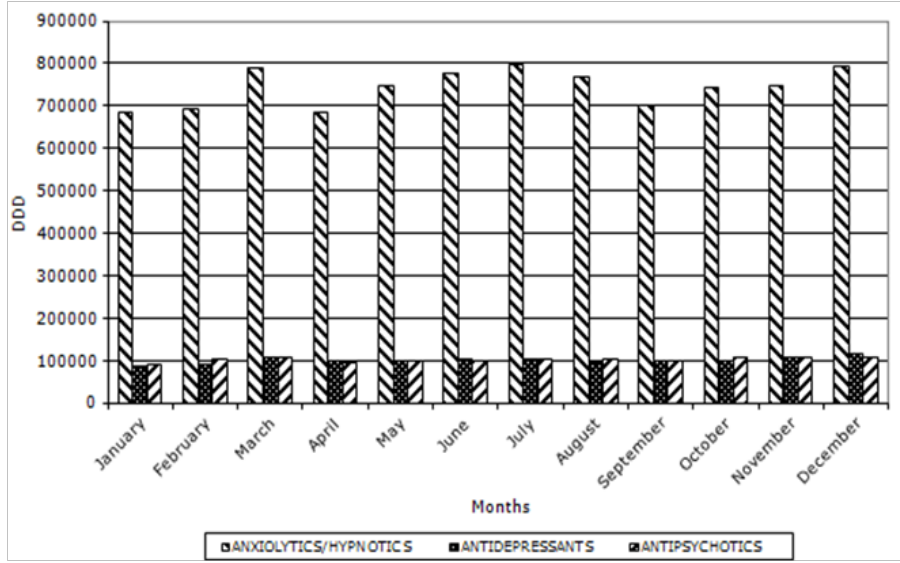

Figure 4 DDD of pharmaceutical specialties distributed by drug providers in 2000 .

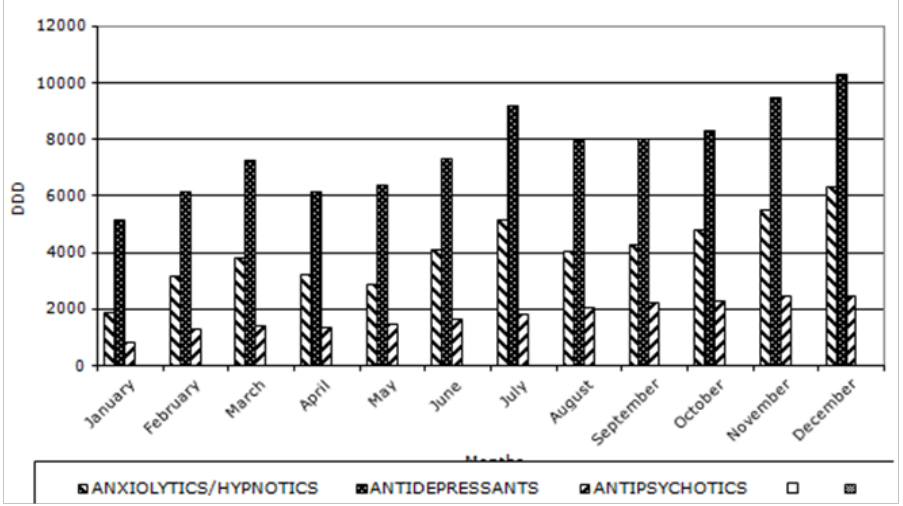

Figure 5 DDD of pharmaceutical compounding dispensed by community pharmacies in 1997

The increase of consumption of anxiolytics/hypnotics and antidepressants in December is due, firstly, to the end of the year that always generates hope for the next year. Moreover Christmas' and New Year's time are full of melancholy and memories for the people. Secondly, as January is a vacation period, all the patients need enough prescriptions to cover this month. It can also explain the increase of dispensing these drugs. In our results we could not find an explanation for the consumption of antipsychotics group, due to the variability of the illness and the wide range of use of these drugs. However it is to note that some physicians prescribed then as digestives, for example Sulpiride, meanwhile other physicians signed them in low doses, as tranquilizers.

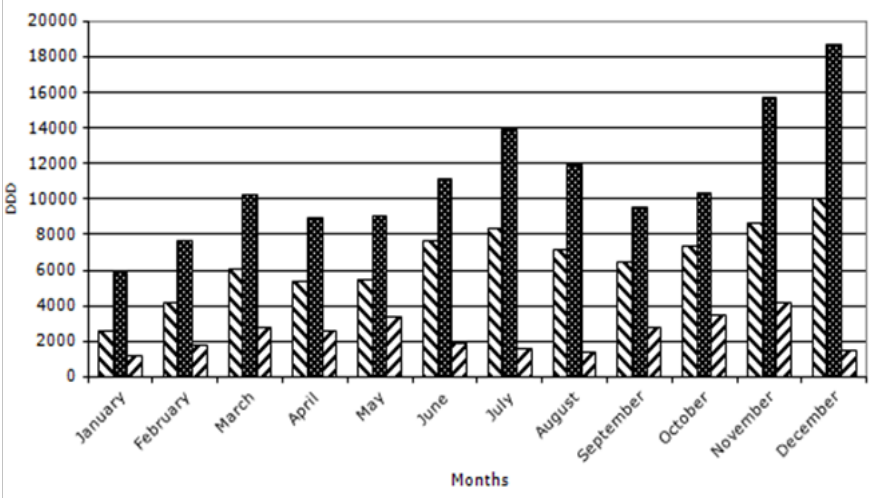

$\triangle A N X I O L Y T I C S / H Y P N O T I C S$ ANTIDEPRESSANTS DANTIPSYCHOTICS

Figure 6 DDD of pharmaceutical compounding dispensed by community pharmacies in 1998.

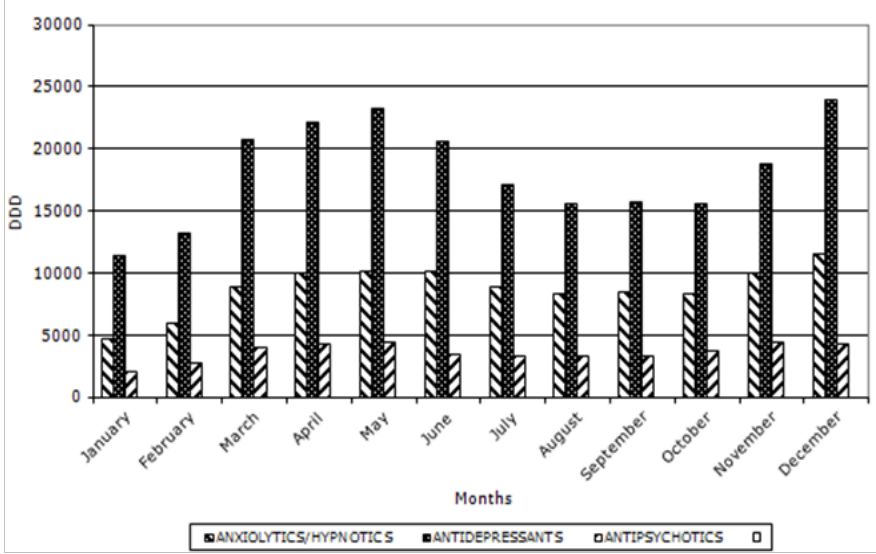

Figure 7 DDD of pharmaceutical compounding dispensed by community pharmacies in 1999.

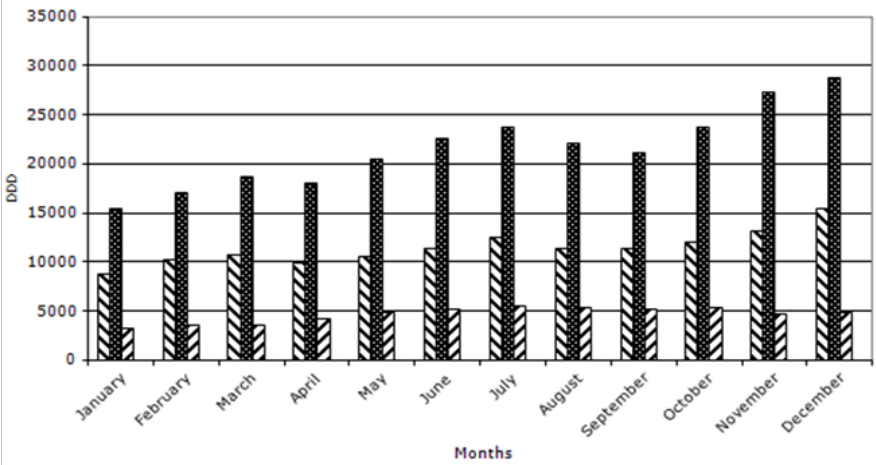

DANDCOLYTICS/HYPNOTICS EANTIDEPRESSANTS DANTIPSYCHOTICS D

Figure 8 DDD of pharmaceutical compounding dispensed by community pharmacies in 2000. 
Our study shows that the less consumption of psychotropic's was in 1998. It could be because that year was the most socio-economic stability for the region. On the contrary, the year 1999, was the worst socio-economic period for the inhabitant of the northeast region that might explain the unusual increase of consumption of psychotropic's in March, April and May. Although the socio-economic situation was better in the year 2000, the general feeling of instability in the regin induces the people to the more consumption of psychotropic's. It is amazing how the socio-economic situation could be displayed by psychotropic consumption, and that should be another signal of attention for the pharmacist to prevent the irrational use of these drugs and to advice about the appropriate use of them.

\section{Conclusions}

The findings of this study will support the rational use $\mathrm{s}^{14,24-26}$ of psychotropic's and in this case the pharmacists can also be an important source of information. Collaboration between physicians and pharmacists can result in improved pharmaceutical care for these patients. ${ }^{27}$ From these results it can be concluded that further monitoring and analysis of consumption of psychotropic drugs should contribute significantly to the implementation of comprehensively appropriate use of these drugs.

\section{Acknowledgments}

None.

\section{Conflicts of interest}

Authors declare that there is no conflict of interest.

\section{References}

1. Baum C, Kennedy DL, Knapp DE, et al. Prescription drugs use in 1984 and changes over time. Med Care. 1988;26(2):105-114.

2. Rokstad K, Straand J, Fugelli P. General practitioners' drugs prescribing practice and diagnosis for prescribing: The More \& Romsdal Prescription Study. J Clin Epidemiol. 1997;50(4):485-494.

3. Osterlind PO, Bucht G. Drugs consumption during the last decade among persons born in Umea, Sweden. A longitudinal population study. Drugs Aging. 1991;1(6):477-486.

4. Skegg DC, Doll R, Perry J. Use of medicines in general practice. Br Med J. 1997;1:1561-1563.

5. Milena M, Ljiljana D. Analysis of drug utilization in Serbia during the years 1996 and 1997. Pharmacoepidemol Drug Safety. 2000;9(1):59-64.

6. Greenblat DJ, Shader RI. Dependence, tolerance and addiction to Benzodiazepines: Clinical and pharmacokinetic consideration. Drug Metab Rev. 1978;8(1):13-28.

7. Russell J, Lader M. Guidelines for the presentation and treatment of Benzodiazepine dependence. London: Mental Health Fundation; 1993.
8. Bohach C. Resources on substance abuse. Am Pharm. 1983;12:59-67.

9. Amitay Y, Erickson T, Kennedy EJ, et al. Tricyclic antidepressants on red cells and plasma: Correlation with impaired intraventricular conduction in acute overdose. Clin Pharmacol Ther. 1993;54(2):219-227.

10. Weintraub M, Handy BM. Benzodiazepines and hip fracture: The New York experience. Clin Pharmacol Ther. 1993;54(3):252-256.

11. Dorevitch A, Meretyk I, Umansky Y, et al. Antipsychotics drugs and tardive dyskinesia: preliminary results in an adolescent psychiatric ward. J Clin Pharm Ther. 1995;20(2):63-65.

12. Flathery JA, Channon RA, Davis JM. Psychiatry: Diagnose and Treatment. México: Editorial Médica Panamericana S.A; 1991.

13. WHO Expert Committee. The Selection of Essential Drugs. Technical Report Series. $N^{\circ}$ 615. Geneva: World Health Organization; 1977. 44 p.

14. Hogerzeil HV. Promoting rational prescribing: an international perspective. Br J Clin Pharmacol. 1995;39(1):1-6.

15. Schatzeberg AF. Fluoxetine in the treatment of comorbid anxiety and depression. J Clin Psychiatry Monograph. 1995;13(2):2-12.

16. Rickels K, Downing R, Schweizer E, et al. Antidepressants for the treatment of generalized anxiety disorder. Arch Gen Psychiatry. 1993;50:884-895.

17. Barbui C, D’Avanzo B, Frattura L, et al. QUALYOP Project 2: Monitoring the dismantling of Italian Psychiatric Hospitals. Psychotropic drugs use in 1.072 inpatients. Pharmacol Drug Safety. 1999;8:331-337.

18. Partonen T, Lonnqvist J. Seasonal affective disorder. Lancet. 1998;352(9137):1369-1374.

19. Blazer DG, Kessler RC, Swartz MS. Epidemiology of recurrent major and minor depression with a seasonal pattern: The National Comorbidity Survey. Br J Psychiatry. 1998;172:164-167.

20. Jepson TL, Ernst ME, Kelly MW. Current perspectives on the management of seasonal affective disorder. J Am Pharm Assoc. 1999;39(6):822-829.

21. Saeed AS, Bruce TJ. Seasonal affective disorders. Am Farm Phys. 1998;57(6):1340-1346.

22. Wehr TA, Rosenthal NE. Seasonality and affective illness. Am J Psychiatry. 1989;146(7):829-839.

23. Teicher MH, Glod CA. Seasonal affective disorder: rapid resolution by low dose alprazolam. Psychopharmacol Bull. 1990;26(2):197-202.

24. Britten N, Brant S, Cairns A, et al. Continued prescribing of inappropriate drugs in general practice. J Clin Pharm Ther. 1995;20(4):199-205.

25. Barber AJ, Rawster D. Essex Benzodiazepines policy. Pharmaceutical J. 1988;241:557-558.

26. Psychiatric Pharmacy Group. Benzodiazepines: Advice for hospital pharmacies. Pharm J. 1990;244:197-198.

27. Fridman GA, Filinger EJ. Pharmacy services in psychiatry outpatients: Interaction physician-pharmacist. Pharm Care Esp. 2002;4:242-244. 